\title{
Coxsackievirus A6 Induces Necroptosis for Viral Production
}

\section{Shuxia Zhang ${ }^{1+}$, Xiaoyan $\mathrm{Yu}^{1+}$, Xiangling Meng ${ }^{1}$, Wenbo Huo ${ }^{1}$, Ying Su${ }^{1}$, Jinming Liu ${ }^{1}$, Yumeng Liu', Jun Zhang', Shaohua Wang ${ }^{2}$ and Jinghua $\mathrm{Yu}^{2 *}$}

${ }^{1}$ Department of Experimental Pharmacology and Toxicology, School of Pharmaceutical Science, Jilin University, Changchun, China, ${ }^{2}$ Institute of Virology and AIDS Research, The First Hospital of Jilin University, Jilin University, Changchun, China

Hand, foot, and mouth disease (HFMD) is a febrile exanthematous disease with typical or atypical symptoms. Typical HFMD is usually caused by enterovirus 71 (EV71) or coxsackievirus A16, while atypical HFMD is usually caused by coxsackievirus A6 (CA6). In recent years, worldwide outbreaks of CA6-associated HFMD have dramatically increased, although the pathogenic mechanism of CA6 is still unclear. EV71 has been established to induce caspase-dependent apoptosis, but in this study, we demonstrate that CA6 infection promotes a distinct pathway of cell death that involves loss of cell membrane integrity. Necrostatin-1, an inhibitor of necroptosis, blocks the cell death induced by CA6 infection, but Z-DEVD-FMK, an inhibitor of caspase-3, has no effect on CA6-induced cell death. Furthermore, CA6 infection up-regulates the expression of the necroptosis signaling molecule RIPK3. Importantly, necrostatin-1 inhibits CA6 viral production, as assessed by its ability to inhibit levels of VP1 protein and genomic RNA and infectious particles. CA6-induced necroptosis is not dependent on the generation of reactive oxygen species; however, viral 3D protein can directly bind RIPK3, which is suggestive of a direct mechanism of necroptosis induction. Therefore, these results indicate that CA6 induces a mechanism of RIPK3-dependent necroptosis for viral production that is distinct from the mechanism of apoptosis induced by typical HFMD viruses.

\section{Keywords: CA6, necroptosis, viral production, RIPK3, host-pathogen interaction}

\section{INTRODUCTION}

Hand, food, and mouth disease (HFMD) is a highly contagious disease caused by enterovirus infection. It especially poses a health problem in young children under 5 years of age worldwide. The most common causative agents of typical HFMD are enterovirus 71 (EV71) and coxsackievirus A 16 (CA16), though coxsackievirus 6 (CA6) has emerged as a causative agent of an atypical form of the disease. In recent years, outbreaks of CA6-associated HFMD have markedly increased worldwide, and especially in China (Gao et al., 2016; Laga et al., 2016; Li J.S. et al., 2016; Li W. et al., 2016; Mirand et al., 2016; Anh et al., 2018; Wang S.H. et al., 2018; Du et al., 2019). Although vaccines and drug have been developed for HFMD, they principally target EV71 and CA16; strategies for preventing and treating CA6-related-HFMD are scarce, and the current understanding of the pathogenic mechanism of CA6 remains limited. 
The typical symptoms of HFMD caused by EV71 or CA16 include flat discolored spots or bumps and sometime, heart inflammation, brain inflammation, or acute flaccid paralysis (Chan et al., 2003; Wang et al., 2012); however, CA6 causes atypical HFMD, characterized by severe rash, onychomadesis in young children, and a higher rate of infection in adults. Furthermore, the pathogenic mechanism of EV71 has been heavily investigated. For example, EV71 has been shown to induce apoptosis that is characterized by cell shrinkage, nuclear condensation, and plasma membrane blebbing in different cell lines (Chang et al., 2004; Lu et al., 2013; Song et al., 2018). EV71-associated apoptosis has also been shown to involve the activation of caspases during viral replication (Chang et al., 2004). Indeed, many viruses induce apoptosis, including but not limited to CA16 (Li et al., 2014), human immunodeficiency virus HIV-1 (Westendorp et al., 1995), hepatitis C virus (Zhu et al., 1998), Epstein-Barr virus (Le Clorennec et al., 2006), and human papillomavirus (Wang et al., 2011). Therefore, apoptosis represents the dominant mechanism by which virus-infected cells undergo programmed cell death. Nevertheless, it remains unknown whether CA6 induces apoptosis.

Coxsackievirus 6 belongs to the Enterovirus genus of the Picornaviridae family, which has a single-stranded, positivesense RNA genome of about $7400 \mathrm{bp}$ that could encode a poly-protein (about 2200 amino acids). In host cells, this polyprotein is further cleaved into four structural (VP1 to VP4) and seven non-structural (2A to $3 \mathrm{D}$ ) proteins by viral non-structural 2A and 3C proteases (Solomon et al., 2010). Besides 2A and $3 \mathrm{C}$ proteins, non-structural 3D protein as an RNA-dependent RNA polymerase is responsible for viral genome replication via incorporating nucleotides into RNA strand (Baltimore, 1964). Recently our studies have demonstrated that 3C and 3D exert other roles that affect the life cycle of the virus (Song et al., 2018; Wang Z. et al., 2018).

As an alternative to apoptosis, necroptosis is an inflammatory type of cell death characterized with cell swelling, loss of plasma membrane integrity, and release of cytosolic contents into the extracellular space (Orzalli and Kagan, 2017). Unlike apoptosis, necroptosis is independent of caspase activity. Generally, when membrane receptors or cytosolic receptors are activated, RIPK1 (receptor-interacting protein kinase 1) associates with RIPK3 via the RIP homotypic interaction motif domain, and this interaction promotes RIPK3-mediated phosphorylation of RIPK1, which then phosphorylates RIPK3. Activated RIPK3 recruits and phosphorylates MLKL, resulting in cell lysis (Cho et al., 2009; He et al., 2009), or activates $\mathrm{Ca}^{2+}$-calmodulin-dependent protein kinase (CaMKII) to induce necroptosis (Zhang et al., 2016). RIPK3-dependent necroptosis has been demonstrated to be activated in response to bovine parvovirus (BPV) (Abdel-Latif et al., 2006), murine cytomegalovirus (Upton et al., 2012), Influenza A virus (Thapa et al., 2016), and reovirus (Berger et al., 2017). Furthermore, high amounts of reactive oxygen species (ROS) have been shown to induce necroptosis (Takemoto et al., 2014; Schenk and Fulda, 2015; Muraro, 2018).

In this study, we demonstrate that the CA6-induced cell death mechanism is distinct from the apoptotic mechanism of EV71 and is instead characterized by RIPK3-dependent necroptosis. CA6-induced necroptosis is not dependent on the generation of ROS, although viral 3D protein can directly bind to RIPK3. Importantly, necrostatin-1 inhibits necroptosis and viral production. These results further advance our understanding of the pathogenic mechanisms of CA6 and provide a potential target for the treatment and prevention of HFMD.

\section{MATERIALS AND METHODS}

\section{Cells and Viruses}

Human rhabdomyosarcoma RD cells (No CCL-136), human embryonic kidney cells (HEK 293T cells) (No CRL-11268), and human cervix epithelial HeLa (No CCL-2) were purchased from the ATCC (Manassas, VA, United States). Cells were grown in Dulbecco's Modified Eagle's Medium (DMEM, Hyclone, Logan, UT, United States) supplemented with $10 \%$ fetal bovine serum (FBS, GIBCO BRL, Grand Island, NY, United States). The 98 strain of $\mathrm{CA}^{1}{ }^{1}$ was provided by the Jilin Provincial Center for Diseases Control and Prevention (Changchun, China). Viruses were propagated in $\mathrm{RD}$ cells, and the supernatants were collected and stored at $-80^{\circ} \mathrm{C}$ as our previous studies (Yu et al., 2015; Wang et al., 2017).

\section{Viral Titer Determination}

As previous study (Zhong et al., 2017), the viral titer in a microtitration assay was determined by measuring the $\mathrm{TCID}_{50}$ in RD cells. Virus was serially prepared after 10-fold dilution, and $100 \mu \mathrm{L}$ virus/well was inoculated in octuplicate in 96-well plates. The cytopathic effect was measured once per day until the experimental endpoint was reached. The $\mathrm{TCID}_{50}$ was determined according to the Reed-Muench method (Reed and Muench, 1983 ) based on that viruses of $1 \times 10^{5} \mathrm{TCID}_{50} / \mathrm{mL}$ will produce $0.7 \times 10^{5}$ plaque forming units $/ \mathrm{mL}$ as our previous studies ( $\mathrm{Yu}$ et al., 2015; Wang et al., 2017).

\section{Propidium lodide Staining}

After gently removing the culture medium, RD cells were stained in situ with $4.5 \mu \mathrm{M}$ of propidium iodide (PI) (40747-B, Yeasen, Shanghai, China) in buffer (40747-C, Yeasen, Shanghai, China) for $15 \mathrm{~min}$ at room temperature in the dark place. The morphological changes were observed and photographed by optical microscopy (Olympus, Tokyo, Japan). PI staining was observed at excitation wavelength $488 \mathrm{~nm}$ with emission filter $630 \mathrm{~nm}$ by fluorescence microscopy (Leica, Nussloch, Germany).

\section{Infection}

Cells were mock-infected or infected with CA6 at an MOI of 5, or EV71 at an MOI of 1 . After $2 \mathrm{~h}$ of virus absorption, cells were washed once with PBS, and cells were cultured with fresh culture medium or drug treated medium.

\section{Drugs Treatment}

After $2 \mathrm{~h}$ of virus absorption, cells were washed once with PBS, and cells were cultured with different dose (100, 150,

\footnotetext{
${ }^{1}$ https://www.ncbi.nlm.nih.gov/nuccore/1071451807
} 
and $200 \mu \mathrm{M}$ ) of necrostatin-1 (A4213, ApexBio, United States), different dose $(100,180$, and $260 \mu \mathrm{M})$ of necrostatin-2 (A3652, ApexBio, United States) or different dose (1, 2, and $4 \mathrm{mM}$ ) of $N$-acetyl-L-cysteine (NAC, A9165, Sigma, St. Louis, MO, United States) for determination of applied concentration. And $20 \mu \mathrm{M}$ of Z-DEVD-FMK (A1920, ApexBio, United States) as apoptosis inhibitor, $150 \mu \mathrm{M}$ of necrostatin-1 as necroptosis inhibitor, $180 \mu \mathrm{M}$ of necrostatin-2 as necroptosis inhibitor, or $2 \mathrm{mM}$ of NAC as ROS scavengers was treated at $2 \mathrm{~h}$ post infection of CA6 or EV71.

\section{Cell Counting Using a Hemocytometer}

Trypan Blue (Sigma, St. Louis, MO, United States) was used as a vital stain. Live cells appeared colorless and bright (refractile) under phase contrast, while dead cells stained blue and were non-refractile. After staining with a final concentration $0.2 \%$ trypan blue, live cells were visualized and counted using a hemocytometer.

\section{Western Blot Analysis}

As our previous studies (Yu et al., 2015; Wang et al., 2017), virus-infected and mock-infected cells and/or together with drug treatment were collected at indicated times. Cells were lysed directly in sodium dodecyl sulfate (SDS) sample buffer [60 mM Tris- $\mathrm{HCl}$ ( $\mathrm{pH}$ 6.8), 2\% SDS, 10\% glycerol, 5\% 2mercaptoethanol, $0.01 \%$ bromophenol blue], followed by boiling for $10 \mathrm{~min}$. Whole-cell lysates were further subjected to SDSPAGE. Proteins were transferred to nitrocellulose membranes (Bio-Rad) and detected with corresponding primary and alkaline phosphatase-conjugated secondary antibody. The membranes were then reacted with 5-bromo-4-chloro-39-indolylphosphate (BCIP) and nitro-blue tetrazolium (NBT) substrate (Sigma, St. Louis, MO, United States). The following antibodies were used: anti-RIPK3 (17563-1-AP, Proteintech), anti-p-MLKL (\#91689, Cell Signal), anti-MLKL (\#14993, Cell Signal), anti-VP1 (GTX132346, Genetex), anti-histone and anti-HA (GenScript), and anti-tubulin (11224-1-AP, Proteintech). Anti-mouse or rabbit secondary antibodies from goat were obtained from Jackson ImmunoResearch.

\section{Immunofluorescence Staining}

RD cells $\left(1 \times 10^{6}\right)$ were cultured in $6 \mathrm{~cm}$ culture dishes for $24 \mathrm{~h}$ and then were mock-infected or infected with CA6 (MOI $=5$ ) for $36 \mathrm{~h}$. At $36 \mathrm{~h}$ after post-infection, cells were fixed with $4 \%$ paraformaldehyde for $15 \mathrm{~min}$. The cells were then rinsed three times with $1 \times$ PBS (5 min per wash) and blocked for $60 \mathrm{~min}$ in blocking buffer $(1 \times \mathrm{PBS} / 5 \%$ normal serum/0.3\% Triton X-100) at room temperature. The cells were then incubated with mouse anti-RIPK3 (17563-1-AP, Proteintech) antibody or together with HA antibody (715500, Invitrogen, United States) overnight at $4^{\circ} \mathrm{C}$. After three washes in PBS, samples were incubated with FITC-goat anti-Mouse IgG $(\mathrm{H}+\mathrm{L})$ (Sungene Biotech, China), or CoraLite 594-conjugated Goat Anti-Mouse IgG $(\mathrm{H}+\mathrm{L})$ (Proteintech, China), or FITC-goat anti-Rabbit IgG $(\mathrm{H}+\mathrm{L})$ (Sungene Biotech, China) for another $2 \mathrm{~h}$ at room temperature. Cells were counterstained with Hoechst 33258 (Sigma, St. Louis, MO, United States) to visualize nuclear DNA on fluorescence microscopy at excitation wavelength $350 \mathrm{~nm}$ with emission filter 460 nm (Leica, Nussloch, Germany).

\section{Quantitative Real-Time RT-PCR}

According to our previous studies (Yu et al., 2015; Wang et al., 2017), intracellular viral genome RNA was detected through targeting VP1 primers, and GAPDH was chose as internalization control. VP1 forward primer: AATGAGGCGAGTGTGGAAC; VP1 reverse primer: AGGTTGGACACAAAAGTGAACT; GAPDH forward primer: GCAAATTCCATGGCACCGT; GAPDH reverse primer: TCGCCCCACTTGATTTTGG. The fold changes were calculated relative to GAPDH using the $2^{-\Delta \Delta \mathrm{Ct}}$ method for VP1, and $\Delta \Delta \mathrm{Ct}=[(\mathrm{VP} 1-\mathrm{GAPDH})$ of drug treatment - (VP1-GAPDH) of control treatment].

\section{Flow Cytometric Analysis by the $2^{\prime}, 7^{\prime}$-Dichlorofluorescin Diacetate Staining}

Mock infected or CA6 infected RD cells were trypsinized and collected. Then the cells were stained with $10 \mu \mathrm{M}$ of $2^{\prime}, 7^{\prime}$ dichlorofluorescin diacetate (DCF-DA) in DMEM with 10\% FBS at $37^{\circ} \mathrm{C}$ for $60 \mathrm{~min}$ in the dark. After incubation, the cells were washed once with PBS. Mock infected RD cells are designed as negative control. The samples were analyzed by flow cytometry at excitation wavelength $480 \mathrm{~nm}$ with emission filter $525 \mathrm{~nm}$ (Yang et al., 2002).

\section{Plasmid Transfection}

According to our previous studies (Yu et al., 2015; Wang et al., 2017), $2 \mu \mathrm{g}$ of VR1012-HA plasmid, VR1012-3C-HA plasmid, or VR1012-3D-HA plasmid with $6 \mu \mathrm{L}$ of Lipofectamine 2000 (Invitrogen, United States) were transfected into cells in $3.5-\mathrm{cm}$ cell culture dishes. We replenished the empty plasmid VR1012 to maintain a final concentration of $2 \mu \mathrm{g}$ plasmid/well for dosedependent test of 3D. Amounts of plasmid and Lipofectamine 2000 were increased for other experiments.

\section{Immunoprecipitation}

293 T cells $(5 \times 105$ cells/well $)$ were cultured in $10 \mathrm{~cm}$ dishes for $24 \mathrm{~h}$ and then were mock-transfected or transfected with $10 \mu \mathrm{g}$ of VR1012-HA, VR1012-3D-HA, or VR1012-3C-HA for $36 \mathrm{~h}$. Then the cells were harvested in IP-lysis buffer [50 $\mathrm{mM}$ Tris ( $\mathrm{pH}$ 7.4), $150 \mathrm{mM} \mathrm{NaCl}, 1 \% \mathrm{NP}-40,0.25 \%$ sodium deoxycholate, $1 \mathrm{mM}$ EDTA], and the lysates were added to mouse antiRIPK3 (sc-374639, Santa Cruz, United States) antibody for immunoprecipitation of RIPK3 in HA-, 3C-HA-, and 3D-HAexpressed cells. The bound proteins were analyzed by Western blotting by RIPK3 (17563-1-AP, Proteintech) and HA (715500, Invitrogen, United States) antibody.

\section{Statistical Analyses}

Statistical differences were analyzed using the Student's $t$-test. Multiple group differences were assessed using one-way ANOVA in SPSS 10.0. Data are presented as means and standard deviations (SD). ${ }^{\star} P$-values of $<0.05$ were considered statistically significant. 


\section{RESULTS}

\section{CA6 Infection Induces Cytopathic Effects, Though the Morphology After CA6 and EV71 Infection Is Different}

Given that EV71, a causative agent for typical HFMD, is known to induce an obvious cytopathic effect in $\mathrm{RD}$ cells (Chang et al., 2004; Lu et al., 2013; Song et al., 2018), we sought to determine whether CA6, a causative agent for atypical HFMD, also induces a cytopathic effect. At $24 \mathrm{~h}$ post infection, CA6 did not cause a statistical decrease in the cell number (data not shown); however, at $36 \mathrm{~h}$ post infection, CA6 decreased the cell number from $5.1 \pm 0.26 \times 10^{5}$ to $3.33 \pm 0.23 \times 10^{5}$ (Figure 1A). By comparison, at $24 \mathrm{~h}$ post infection, EV71 decreased the cell number from $4.83 \pm 0.45 \times 10^{5}$ to $1.93 \pm 0.15 \times 10^{5}$ (Figure 1B). These results suggest that CA6 can induce a cytopathic effect, although the time course for CA6-mediated cytopathy is extended relative to the time course for EV71mediated cytopathy.

To determine whether the cytopathic effect caused by CA6 at $36 \mathrm{~h}$ post infection is similar to the cytopathic effect caused by EV71 at 24 h post infection, we performed morphology analysis. At $36 \mathrm{~h}$ after CA6 infection, many cells were floating, and others appeared ruptured (Figure 1C). In contrast, at $24 \mathrm{~h}$ after EV71 infection, the cells were condensed, rounded up, and detached from the bottom of the dish (Figure 1D). Therefore, although both viruses induced cytopathy, the mechanism of cell death induction by CA6 and EV71 appeared to differ.

To further distinguish the cell death induced by CA6 infection and EV71 infection, we utilized PI to assess plasma membrane rupture. After CA6 infection, the dying cells showed signs of cellular membrane permeability (Figure 1E), which is a mark of necroptosis (Abdel-Latif et al., 2006; Cho et al., 2009; He et al., 2009). In contrast, cellular PI staining was not observed after EV71 infection (Figure 1F), which is more suggestive of apoptosis and is consistent with the findings of previous studies (Chang et al., 2004; Song et al., 2018). Therefore, these results raise the possibility that CA6 might induce cytopathic effects through necroptosis, rather than apoptosis.

\section{CA6 Infection Induces a Necroptotic Form of Cell Death}

To further evaluate the possibility that CA6 induces necroptosis, the necroptosis inhibitor, necrostatin-1 (150 $\mu \mathrm{M}, \mathrm{A} 4213$, ApexBio, United States), and the apoptosis inhibitor, Z-DEVDFMK (20 $\mu \mathrm{M}, \mathrm{A} 1920$, ApexBio, United States), were added (Figures 2A,B). The results demonstrated that necrostatin-1 inhibited the morphological changes and PI permeability induced by CA6, although Z-DEVD-FMK had no effect (Figure 2C). On the other hand, Z-DEVD-FMK, but not necrostatin-1, inhibited the morphological changes induced by EV71 infection (Figure 2D). These results suggest that CA6 induces cell death by a mechanism that differs from the mechanism of apoptosis induced by EV71.

To verify that necrostain-1 modulates the cytopathic effect caused by CA6 virus, we examined the effect of necrostatin-1 on the cell number. Our results demonstrated that necrostatin-1 reversed the decrease in the cell number caused by CA6 infection $\left(4.53 \pm 0.06 \times 10^{5}\right.$ versus $\left.3.33 \pm 0.31 \times 10^{5} ; P<0.01\right)$, but Z-DEVD-FMK could not reverse the decrease induced by CA6 infection (Figure 2E). However, Z-DEVD-FMK reversed the decrease in the cell number caused by EV71 infection $\left(3.90 \pm 0.10 \times 10^{5}\right.$ versus $\left.1.93 \pm 0.15 \times 10^{5} ; P<0.001\right)$, but necrostatin-1 could not reverse this decrease induced by EV71 infection (Figure 2F). Therefore, these results are consistent with the ability of CA6 to induce necroptosis.

\section{RIPK3, a Protein in the Pathway of Necroptosis, Is Up-Regulated After CA6 Infection}

Next, we investigated the mechanism of necroptosis induced by CA6 infection by assessing the effects of CA6 infection on necroptosis proteins. The expression of RIPK 3 was up-regulated by CA6 infection, with a similar time course of upregulation as that of the viral protein VP1, while the expression of P-MLKL and MLKL was not consistently altered (Figure 3A), and especially at $48 \mathrm{~h}$ post infection, the expression of RIPK3 was significantly up-regulated by CA6 infection comparing to mock infection $(P<0.01$, Figure 3B); however, EV71 infection did not affect RIPK3 expression as well as the expression of P-MLKL and MLKL with time (Figure 3C), which proved that CA6 could regulate necroptotic pathway protein, but not EV71. Furthermore, the expression of the apoptotic proteins pro-caspase-3 and cleaved caspase-3 was not changed after CA6 infection (Supplementary Figure S1A), but was changed after EV71 infection (Supplementary Figure S1B), which further confirmed that CA6 infection did not induce apoptosis and was different from EV71. For further confirmation that RIPK3 is upregulated by CA6 infection, we performed immunofluorescence analysis. The results confirm CA6 infection induced necroptosis (Figure 3D2) compared to mock infection (Figure 3D1), and the increased expression of RIPK3 was visualized in necroptotic cells induced by CA6-infection (Figure 3D4) compared to mock-infection (Figure 3D3). Furthermore, the up-regulated RIPK3 was also localized to the cytoplasm, where viral genome replication, protein translation, and viral package occur (Figure 3D8). We additionally assessed the effects of necrostatin-1 on RIPK 3 expression. At $36 \mathrm{~h}$ post infection, the expression of RIPK3 underwent consistent decreased in response to necrostatin- 1 treatment $(P<0.05$, Figures 3E,F). Therefore, the necroptosis induced by CA6 infection is associated with the up-regulation of RIPK3.

\section{Necroptosis Promotes Viral Production}

Necrostatin-1 is (R)-5-([7-chloro-1H-indol-3-yl]methyl)3-methylimidazolidine-2,4-dione (Figure 4A). Below the concentration of $200 \mu \mathrm{M}$, the inhibitory ratio of necrostatin-1 is $<5 \%$, the inhibitory ratio of $360 \mu \mathrm{M}$ of necrostatin-1 is about $37 \%$ at $36 \mathrm{~h}$ post-treatment (Supplementary Figure S1C). To evaluate whether the necroptosis induced by CA6 infection affects viral production, we examined the effect of different doses of necrostatin-1 treatment $(100,150$, and $200 \mu \mathrm{M})$ on viral 
A

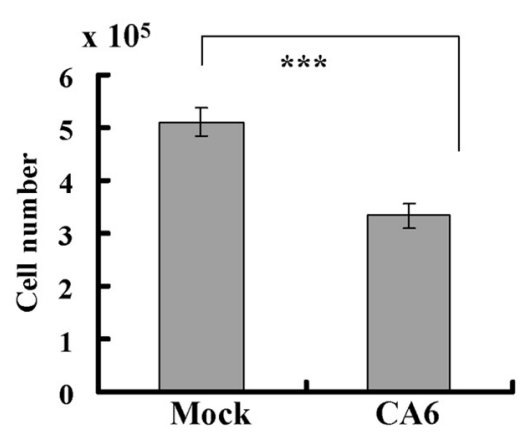

C

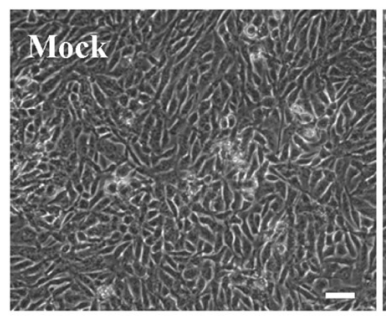

E

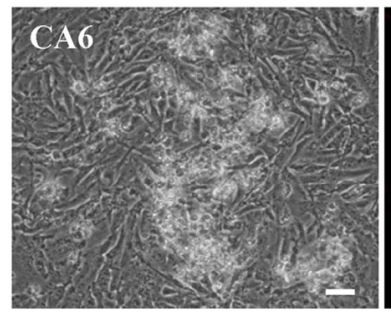

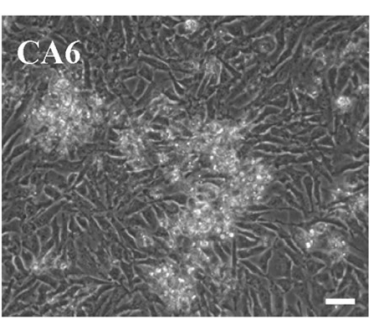

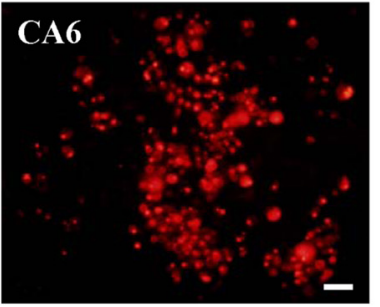

B

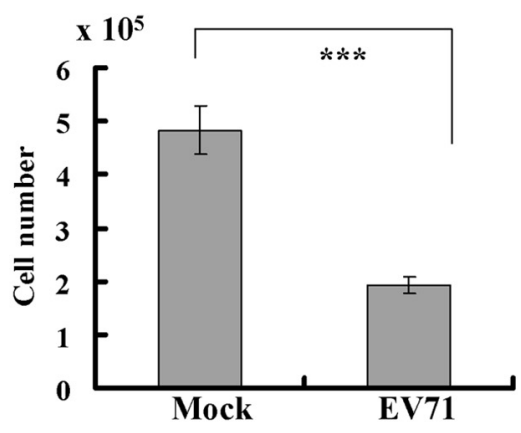

D
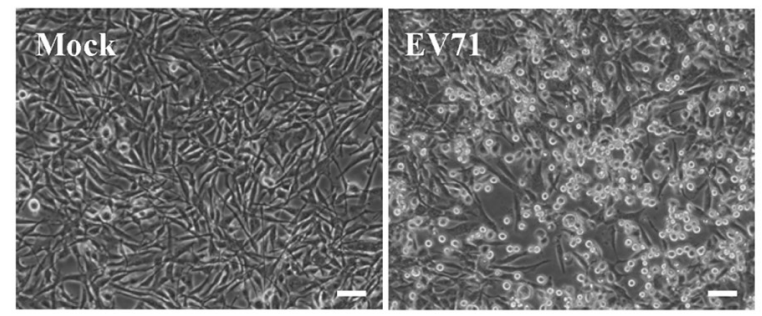

$\mathbf{F}$

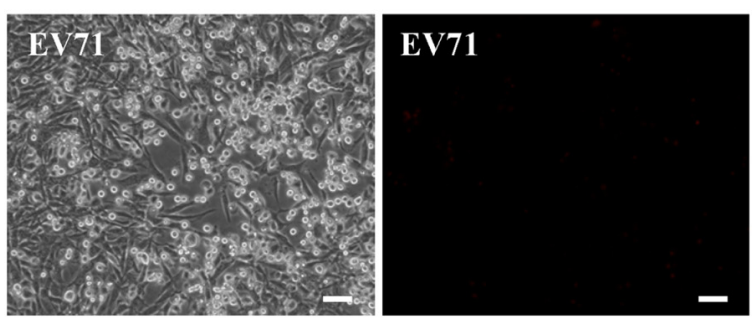

FIGURE 1 | CA6 induces cytopathic effects in RD cells. (A) Cell number analysis after CA6 infection $(\mathrm{MOI}=5)$ at $36 \mathrm{~h}$. The cell numbers were counted by trypan blue staining. The results represent the mean $\pm S D$ of three independent experiments. ${ }^{\star \star *} P<0.001$. (B) Cell number analysis after EV71 infection (MOI $=1$ ) at $24 \mathrm{~h}$. The cell numbers were counted by trypan blue staining. The results represent the mean $\pm \mathrm{SD}$ of three independent experiments. ${ }^{\star \star *} P<0.001$. (C) Cell morphologic analysis after mock or CA6 $(\mathrm{MOI}=5)$ infection was performed at $36 \mathrm{~h}$ post infection. Results are representative of three independent experiments. Bar $=20 \mu \mathrm{m}$. (D) Cell morphologic analysis after mock or EV71 $(\mathrm{MOI}=1)$ infection was performed at $24 \mathrm{~h}$ post infection. Results are representative of three independent experiments. Bar $=20 \mu \mathrm{m}$. (E) Cell morphologic analysis with propidium iodide staining after CA6 $(\mathrm{MOI}=5)$ infection was performed at $36 \mathrm{~h}$ post infection by light microscopy (left) or fluorescence microscopy (right). Results are representative of three independent experiments. Bar $=20 \mu \mathrm{m}$. (F) Cell morphologic analysis with propidium iodide staining after EV71 ( $\mathrm{MOI}=1$ ) infection was performed at $24 \mathrm{~h}$ post infection and assessed by light microscopy (left) or fluorescence microscopy (right). Results are representative of three independent experiments. Bar $=20 \mu \mathrm{m}$.

protein expression at $36 \mathrm{~h}$ post infection. The expression of VP1 was decreased by necrostatin-1 in a dose-dependent manner (Figure 4B). To verify these findings, the effects of necrostatin-1 on CA6 genomic levels were evaluated. Necrostatin-1 obviously inhibited the intracellular viral genomic level as assessed by realtime PCR of the VP1 coding sequence $(P<0.001)$ (Figure 4C). Finally, we analyzed CA6 virus production at $36 \mathrm{~h}$ post-infection. The TCID50/mL of CA6-infected cells $\left(45.27 \pm 16.16 \times 10^{5}\right)$ was dramatically reduced by the addition of necrostatin-1 $\left(4.66 \pm 0.81 \times 10^{5}\right)(P<0.05)$ (Figure 4D). At the same time, another necroptosis inhibitor, necrostatin-2, was utilized to confirm necroptosis affecting CA6 viral production. Necrostatin2 is an analog of necrostatin-1 (Teng et al., 2007; Figure 4E) and has more powerful ability of inhibiting necroptosis and less cytotoxicity than necrostatin-1. Below the concentration of $280 \mu \mathrm{M}$, the inhibitory ratio of necrostatin-2 is $<5 \%$, the inhibitory ratio of $360 \mu \mathrm{M}$ of necrostatin-2 is about $16 \%$ at $36 \mathrm{~h}$ post-treatment (Supplementary Figure S1D). And it was confirmed that necrostatin-2 had a similar inhibitory ability on viral production (Figures $4 \mathbf{F}-\mathbf{H}$ ). To further confirm the mechanism of necroptosis affecting viral production, we analyzed the effect of necrostatin-1 on viral release. Considering the alteration of cell number after virus infection and necrostain1 treatment, before calculating intracellular and extracellular viral genome level and TCID50, the cell number was detected, and it was found that different dose of necrostatin-1 (Supplementary Figure S2A) and necrostatin-2 (Supplementary Figure S2B) could prevent the damage induced by CA6 infection, but not caspase-3 inhibitor (Supplementary Figure S2C). Especially, the survival ratio of CA6 infected cells is $66 \%$, while together 


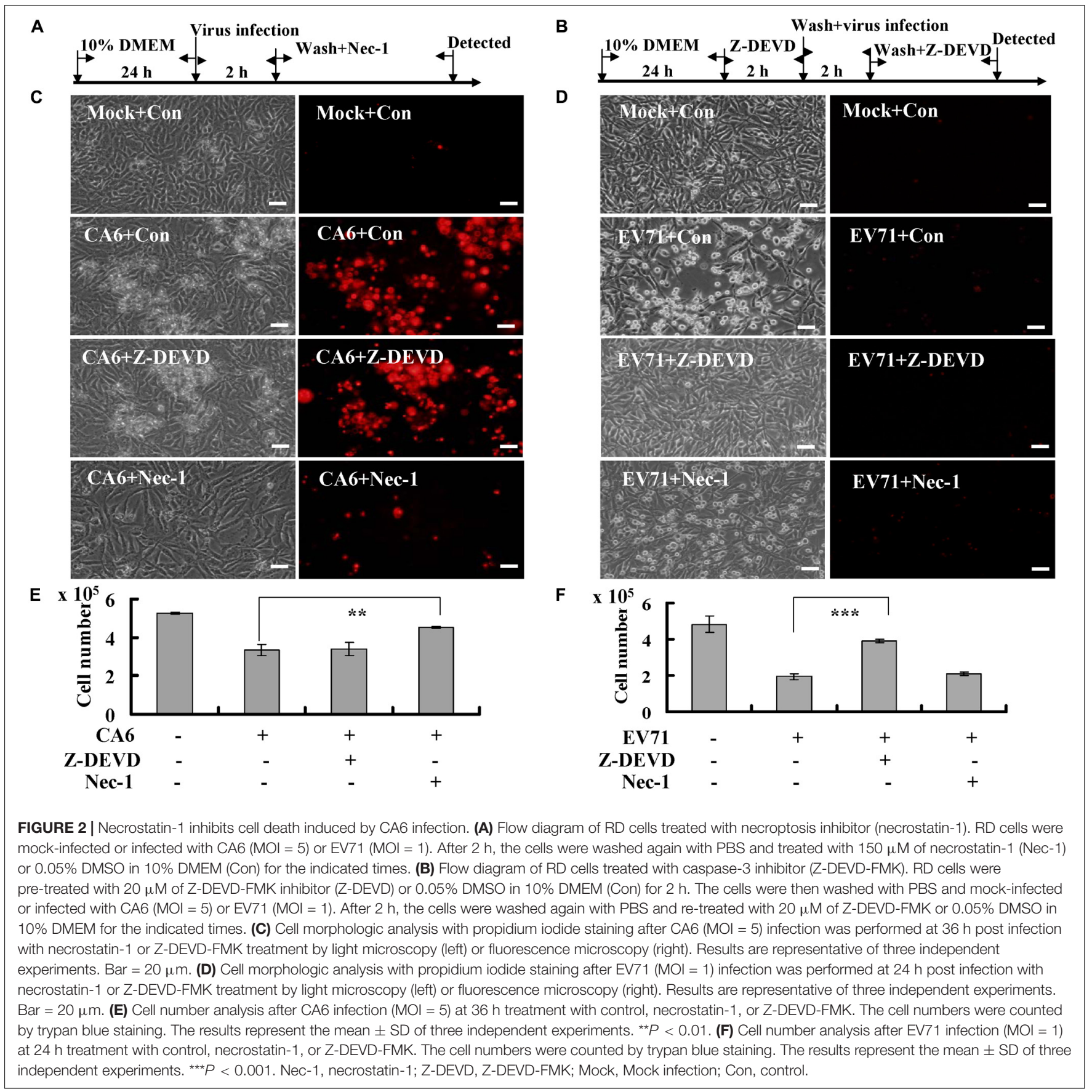

with $150 \mu \mathrm{M}$ of necrostatin-1 the survival ratio of CA6 infected cells is $85 \%$ at $36 \mathrm{~h}$ post infection (Supplementary Figure S2A). Followed that, we detected the mRNA level of CA6 in extracellular, intracellular, and total samples by real-time PCR, then the relative extracellular and intracellular mRNA level was calculated assuming the same cell number in each group of control and necrostatin-1 treatment $(150 \mu \mathrm{M})$, and it was found that excluding the effect of cell number, for extracellular mRNA level, control treatment was 123 times as large as the necrostatin-1 treatment, and for intracellular mRNA level, control treatment was 2.73-fold of the necrostation-1 treatment, while for total mRNA level, control treatment was 2.54 times than the necrostation-1 treatment (Figure 4I). Meanwhile, for extracellular virions production, control treatment was 229 times as large as the necrostatin-1 treatment, and for intracellular virions production, there was no obvious difference between control treatment and necrostation-1 treatment, while for total virions production, control treatment was 10 times than the necrostation-1 treatment (Figure 4J and Supplementary Figure S2D). Therefore, these results suggest that CA6-induced necroptosis promotes viral production, especially through inhibiting viral release. 

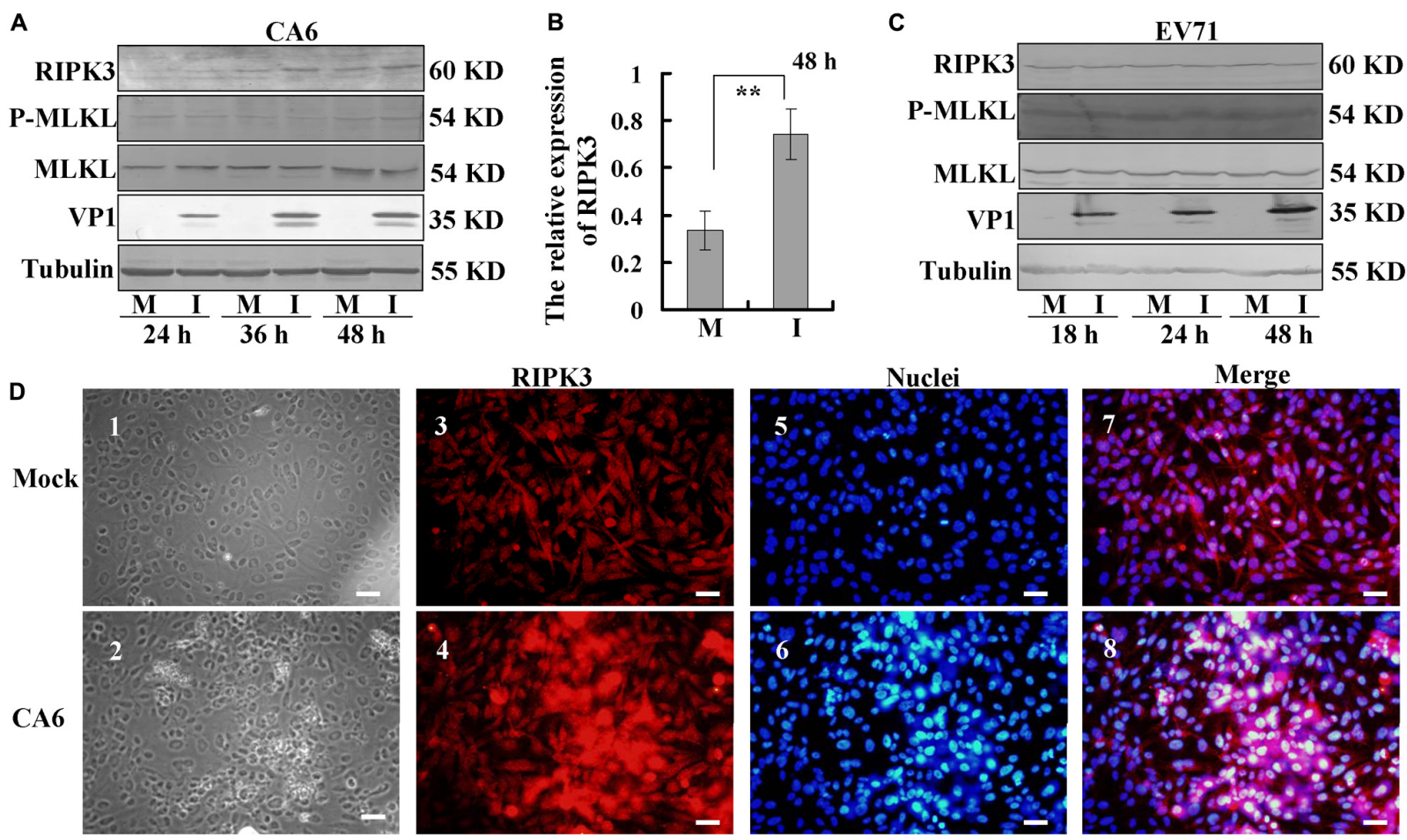

E
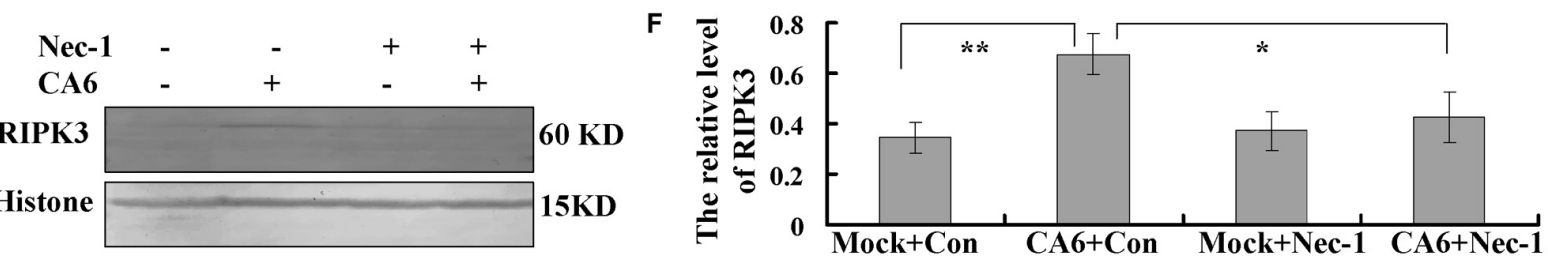

FIGURE 3 | Analysis of host necroptosis regulatory proteins. (A) RD cells were mock-infected (M) or infected with CA6 at a MOI of 5 (I) and then collected at the indicated times. RIPK3, p-MLKL, MLKL, and VP1 were detected by Western blot analysis. Tubulin is shown as a loading control. Results are representative of three independent experiments. (B) RD cells were mock-infected (M) or infected with CA6 at a MOI of 5 (I) and then collected at the $48 \mathrm{~h}$ post infection. The band of RIPK 3 and corresponding tubulin was processed by ImageJ, and the ratio of intensity of RIPK3 to corresponding tubulin was shown. The results represent the mean \pm SD of three independent experiments. ${ }^{\star \star} P<0.01$. (C) RD cells were mock-infected (M) or infected with EV71 at a MOI of 1 (I) and then collected at the indicated times. RIPK3, p-MLKL, MLKL, and VP1 were detected by Western blot analysis. Tubulin is shown as a loading control. Results are representative of three independent experiments. (D) RIPK3 distribution as assessed by fluorescence microscopy at $36 \mathrm{~h}$ post-infection with CA6 at a MOI of 5 . Cells were stained with RIPK3 antibody, and then co-stained with CoraLite594-conjugated-second antibody (Red). DNA was counterstained with Hoechst 33258 (Blue). Cell morphology was visualized by light microscope. Merged images of RIPK3 with DNA are shown. Results are representative of three independent experiments. Scale bar $=20 \mu \mathrm{m}$. (E) Necrostatin-1 inhibited the expression of RIPK3-induced by CA6. Histone is shown as a loading control. Results are representative of three independent experiments. (F) The band of panel (E) was processed by ImageJ, and the ratio of intensity of RIPK3 to corresponding histone was shown. The results represent the mean $\pm \mathrm{SD}$ of three independent experiments. ${ }^{\star *} P<0.01 .{ }^{*} P<0.05$.

\section{ROS Scavenger Do Not Inhibit CA6 Proliferation}

Often, necroptosis is associated with increases in the level of ROS (Takemoto et al., 2014; Schenk and Fulda, 2015; Muraro, 2018). To investigate the relationship between CA6 infection and ROS, the level of ROS was detected, CA6 infection did not change the level of ROS compared to the mock-infection (Figure 5A). To further confirm the relationship between CA6 infection and ROS, scavengers of ROS (NAC, N-Acetyl-L-cysteine, Sigma, St. Louis, MO, United States, A9165) were applied to CA6-infected cells. Increasing doses of NAC had no effect on the expression of VP1 (Figure 5B), the necroptotic death induced by CA6 (Figures 5C,D), or virion production (Figure 5E). To prove the effectiveness of ROS detection and NAC, pseudolaric acid ( $3 \mu \mathrm{M})$ was used as positive control (Qi et al., 2013), and it was found that pseudolaric acid increased the level of ROS $(P<0.001)$ and NAC inhibited the increase of ROS $(P<0.05)$ (Supplementary Figures S3A,B). Therefore, these results suggest that necroptosis induced by CA6 is not dependent on ROS.

\section{Viral Non-structural Protein 3D Directly Hijacks RIPK3}

As an alternative to ROS induction, we speculated that CA6 virus might directly hijack the pathway of necroptosis by targeting RIPK3 protein. Viral non-structural protein $3 \mathrm{C}$ as a protease and $3 \mathrm{D}$ as an RNA-dependent RNA polymerase play important role in 
A<smiles>CN1C(=O)[C@H](Cc2c[nH]c3ccccc23)NC1=S</smiles>

B

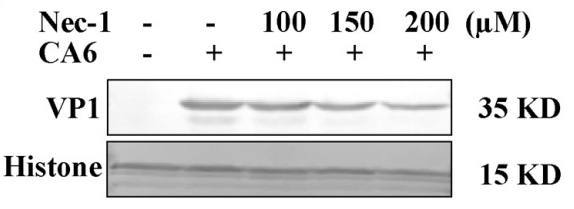

E<smiles>CN1C(=O)NC(Cc2c[nH]c3c(Cl)cccc23)C1=O</smiles>

F

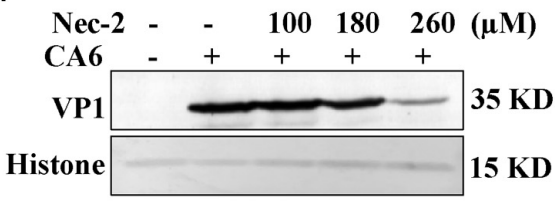

C

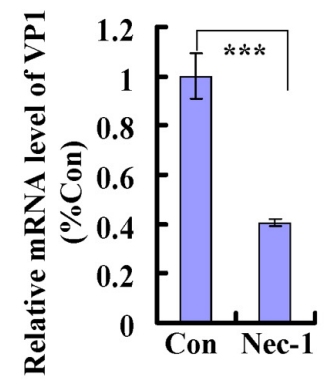

G

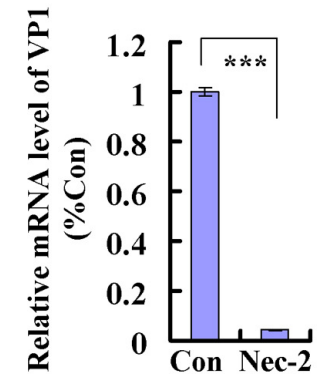

D

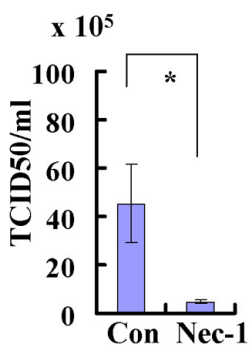

H

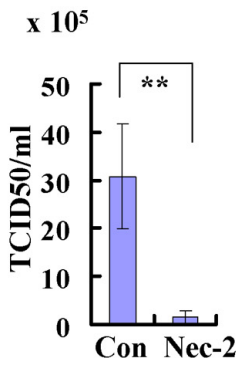

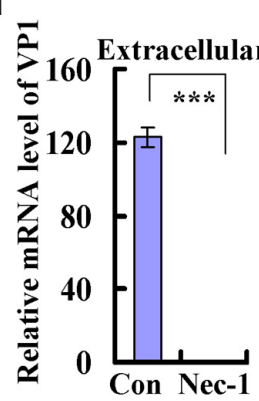
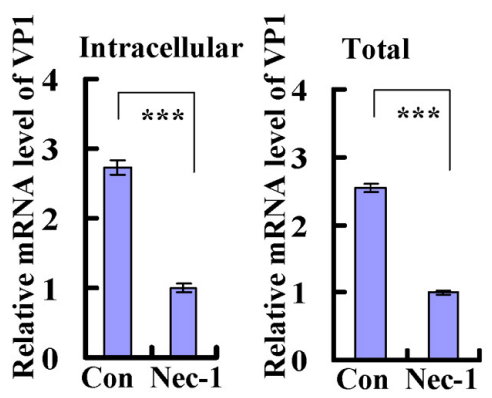

J

Extracellular Intracellular

Total
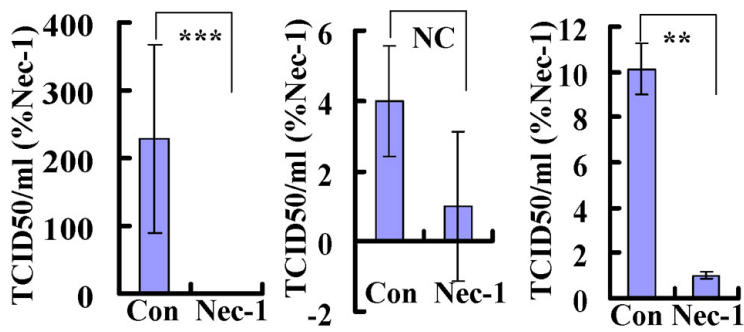

FIGURE 4 | Necrostatin-1 or necrostatin-2 inhibits viral production. (A) The chemical structure of necrostatin-1. (B) VP1 expression in cellular lysates was determined after growth in control medium or different doses of necrostatin-1 medium at $36 \mathrm{~h}$ post-infection. The results are representative of three independent experiments. Histone is shown as loading control. (C) At $36 \mathrm{~h}$ post-infection, intracellular CA6 RNA levels were detected in control, necrostatin-1 (150 $\mu$ M)-treated $\mathrm{RD}$ cells by real-time quantitative PCR. The results were standardized to GAPDH mRNA as a control and normalized to 1.0 in Con-treated cells. ${ }^{* \star *} P<0.001$. (D) Total progeny viruses collected at $36 \mathrm{~h}$ post-infection of CA6 $(\mathrm{MOI}=5)$ were titrated using RD cells. The results indicate the means \pm SD of three independent experiments. ${ }^{*} P<0.05$. (E) The chemical structure of necrostatin-2. (F) VP1 expression in cellular lysates was determined after growth in control medium or different doses of necrostatin-2 medium at $36 \mathrm{~h}$ post-infection. The results are representative of three independent experiments. Histone is shown as loading control. (G) At $36 \mathrm{~h}$ post-infection, intracellular CA6 RNA levels were detected in control, necrostatin-2 (180 $\mu \mathrm{M})$-treated RD cells by real-time quantitative PCR. The results were standardized to GAPDH mRNA as a control and normalized to 1.0 in Con-treated cells. ${ }^{\star \star \star} P<0.001$. (H) Total progeny viruses collected at 36 h post-infection of CA6 $(\mathrm{MOI}=5)$ were titrated using RD cells. The results indicate the means $\pm \mathrm{SD}$ of three independent experiments. ${ }^{* \star} P<0.01$. (I) At $36 \mathrm{~h}$ post-infection, extracellular, intracellular, and total CA6 RNA levels were detected in control, necrostatin-1 (150 $\mu \mathrm{M})$-treated RD cells by real-time quantitative PCR. The results of extracellular and intracellular were standardized to corresponding cell number and normalized to 1.0 in Nec-1-treated cells. ${ }^{\star \star \star} P<0.001$. (J) At $36 \mathrm{~h}$ post-infection, extracellular, intracellular, and total virions were detected in control, necrostatin-1 (150 $\mu \mathrm{M})$-treated RD cells by TCID50. The results of extracellular and intracellular were standardized to corresponding cell number and normalized to 1.0 in Nec-1-treated cells. ${ }^{\star \star \star} P<0.001$, ${ }^{\star \star} P<0.01$. NC, no significant difference; Con, control treatment; Nec-1, necrostatin-1; Nec-2, necrostatin-2.

viral life cycle (Song et al., 2018; Wang Z. et al., 2018), and 3C and 3D of CA6 induce G0/G1 cell cycle arrest (Wang Z. et al., 2018). Therefore, we firstly evaluated the interaction between these proteins by immunoprecipitation assay, RIPK3 protein antibody was able to pull down 3D-HA but not $10 \mathrm{KD}$ of HA which was constructed by our previous study (Song et al., 2018; Figure 6A). However, RIPK3 protein antibody was not able to pull down 3C-HA (Figure 6B). Therefore, RIPK3 possibly was hijacked by viral $3 \mathrm{D}$ protein but not $3 \mathrm{C}$ protein. In the following study, it was found that with the increase of $3 \mathrm{D}$ protein, the expression of RIPK3 was correspondingly up-regulated (Figure 6C), and with the $3 \mathrm{D}$ increase, necroptosis occurred more and more
(Figure 6D). We further evaluated that RIPK3 can co-localize with the viral non-structural 3D. The results demonstrate that RIPK3 was up-regulated by 3D-HA and co-localized with 3D-HA but not HA (Figure 6E). On the basis of these results, 3D protein may regulate necroptosis by binding RIPK3.

\section{DISCUSSION}

Apoptosis is a prevalent form of programmed cell death that is activated by many viruses, such as CA16 (Li et al., 2014), human immunodeficiency virus (HIV-1) (Westendorp et al., 1995), 
A
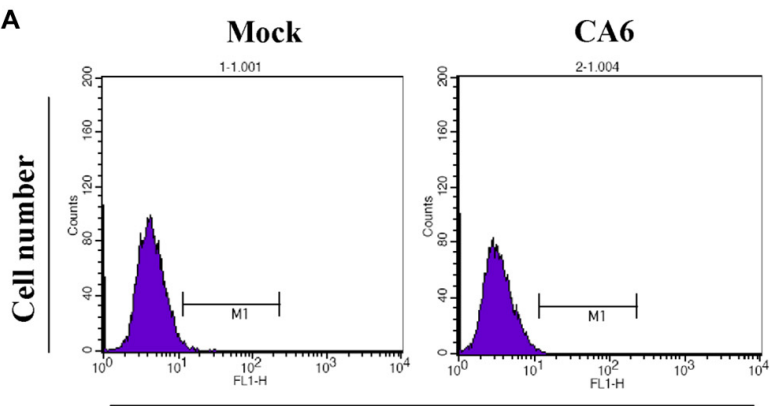

ROS level
B

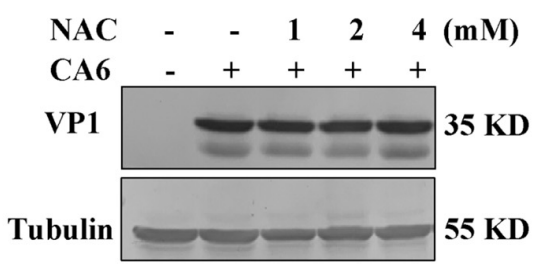

C

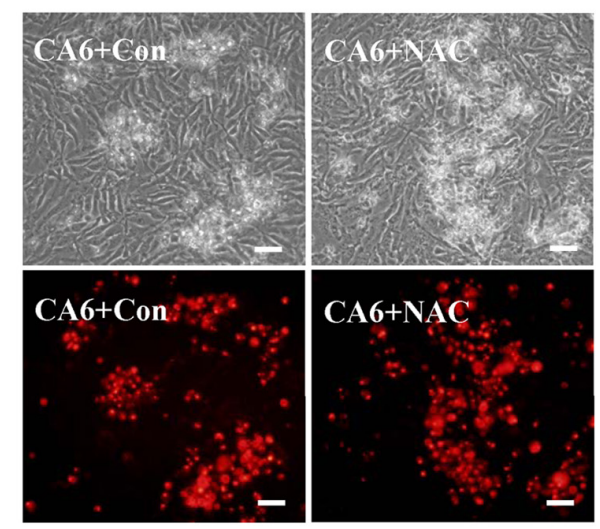

D

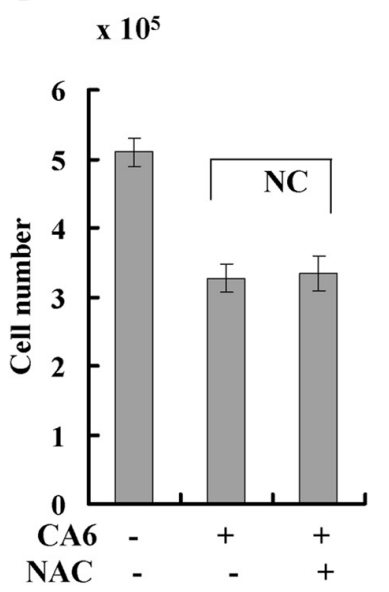

E

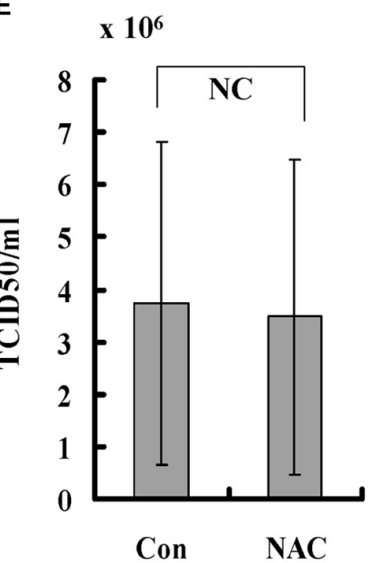

FIGURE 5 | Scavengers of ROS (NAC) do not inhibit necroptosis or viral production. (A) The level of ROS was determined after CA6 infection (MOI = 5) at $36 \mathrm{~h}$ post-infection by flow cytometery. The results are representative of three independent experiments. (B) VP1 expression in cellular lysates was determined after growth in control medium or different doses of NAC medium at $36 \mathrm{~h}$ post-infection. The results are representative of three independent experiments. Tubulin is shown as loading control. The results are representative of three independent experiments. (C) Cell morphologic analysis with propidium iodide staining after CA6 $(\mathrm{MOI}=5)$ infection was performed at $36 \mathrm{~h}$ post infection with control or NAC treatment (2 mM) by light microscopy (upper) or fluorescence microscopy (lower). Results are representative of three independent experiments. Bar $=20 \mu \mathrm{m}$. (D) Cell number analysis after CA6 infection at $36 \mathrm{~h}$. The cell numbers were counted by trypan blue staining. The results represent the mean \pm SD of three independent experiments. NC, no significant difference. (E) Total progeny viruses collected at $36 \mathrm{~h}$ post-infection of CA6 were titrated using RD cells. The results indicate the mean $\pm \mathrm{SD}$ of three independent experiments. NC, no significant difference.

hepatitis C virus (Zhu et al., 1998), Epstein-Barr virus (Le Clorennec et al., 2006), and human papillomavirus (Wang et al., 2011). Previous studies show that EV71, which is a major pathogen of typical HFMD, induces apoptosis (Chang et al., 2004) and activates caspase-3 for own production (Song et al., 2018). However, when we investigated the death mechanism of the CA6 virus, the major causative agent of atypical HFMD, we found that CA6 does not induce the same program of apoptosis as EV71.

Apoptotic cells display characteristic morphological features, including membrane blebbing, condensed cells, and the formation of apoptotic bodies, which can be observed after EV71 infection. However, our results reveal that after CA6 infection, membrane rupture and organelle swelling occur, which are the hallmarks of necroptosis. Furthermore, the cell death induced by CA6 infection was attenuated by necrostatin-1, but not caspase-3 inhibitor. Therefore, our results suggest that CA6 induces necroptosis rather than apoptosis.
The induction of necroptosis by CA6 virus could potentially explain the atypical manifestation of HFMD. HFMD is a febrile exanthematous disease with typical or atypical symptoms in children younger than 5 years of age. EV71 infection induces typical symptoms of HFMD, including flat discolored spots or bumps, even heart inflammation, brain inflammation, or acute flaccid paralysis (Chan et al., 2003; Wang et al., 2012), while CA6 leads to atypical HFMD characterized by severe rash, onychomadesis in young children, and a higher rate of infection in adults. In recent years, the large outbreaks of HFMD are usually caused by EV71 infection, while CA6-associated HFMD has lower rates that have markedly increased worldwide. Therefore, apoptosis or necroptosis might be related to varying clinical characteristics, such as the epidemic region, epidemic frequency, clinical symptoms, and epidemic size.

Although CA6 diverges from the typical HFMD viruses in its ability to promote necroptosis, there are many other viruses that activate necroptosis. BPV (Abdel-Latif et al., 2006), 


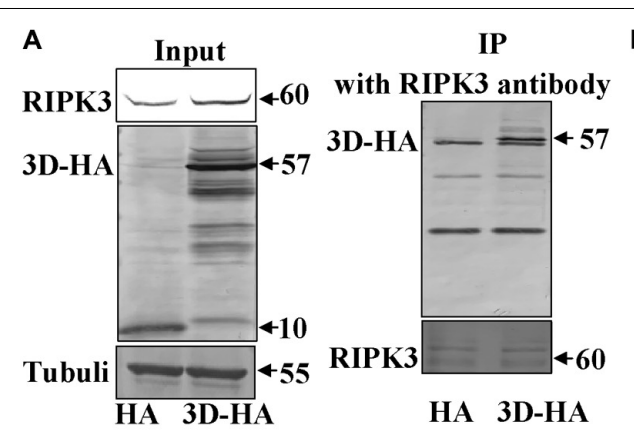

D
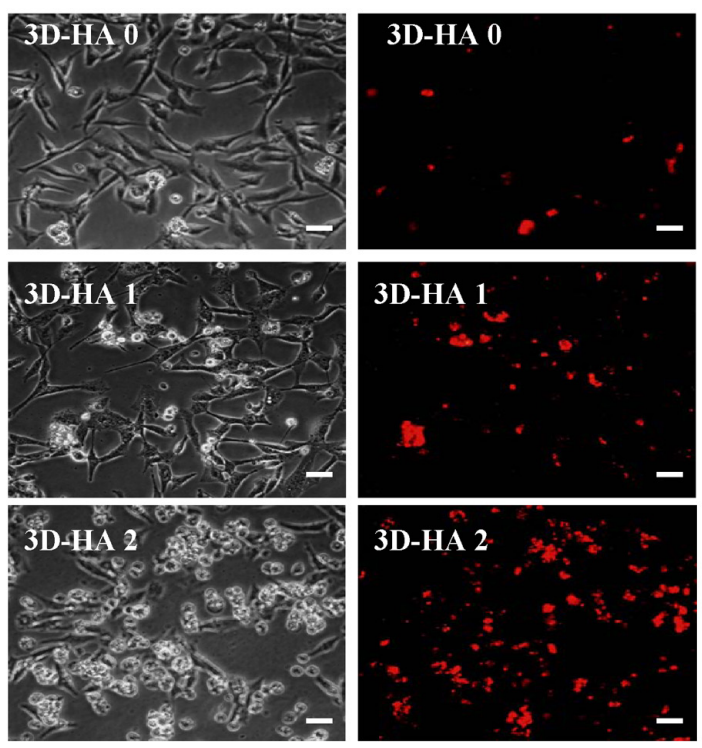

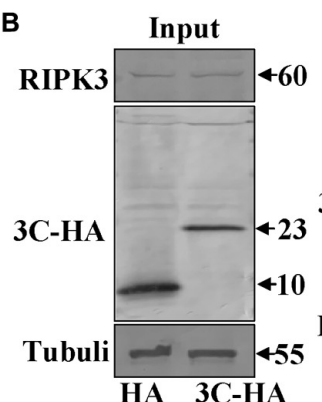

HA 3C-HA
IP

E
HA
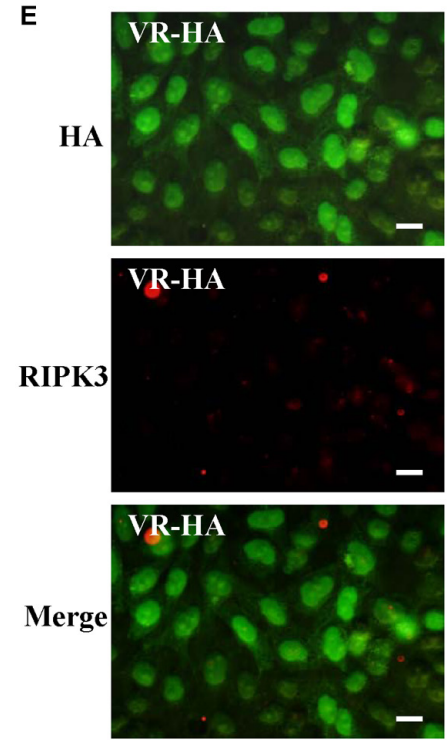

C

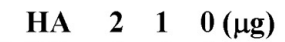

3D-HA $\quad 0 \quad 1 \quad 2(\mu \mathrm{g})$

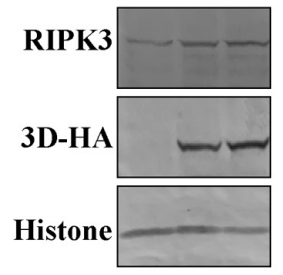

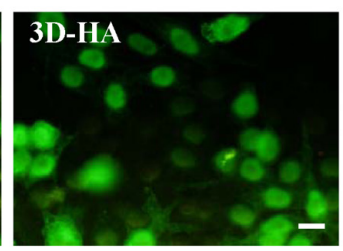
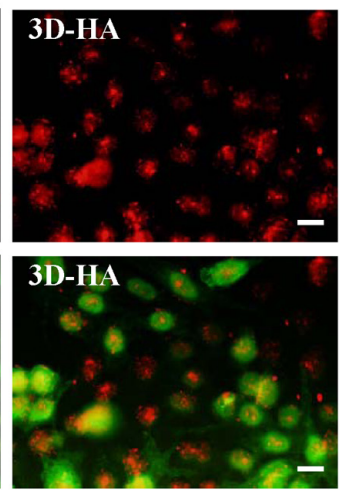

FIGURE 6 | Non-structural protein 3D binds RIPK3. (A) Non-structural protein 3D in 3D-transfected cells was evaluated by Western blotting before or after immunoprecipitation (IP) with RIPK3 antibody (Santa) at $36 \mathrm{~h}$ post transfection. Results are representative of three independent experiments. (B) Non-structural protein 3C in 3C-transfected cells was evaluated by Western blotting before or after immunoprecipitation (IP) with RIPK3 antibody (Santa) at 36 h post transfection. Results are representative of three independent experiments. (C) The expression of RIPK3 in $293 \mathrm{~T}$ cells was analyzed at $36 \mathrm{~h}$ after transfection with 0,1 , or $2 \mu \mathrm{g}$ of 3D-HA-VR1012 plasmid as indicated. Results are representative of three independent experiments. Histone is loading control. (D) Transfection of 0, 1 , or $2 \mu \mathrm{g}$ of 3D-HA-VR1012 plasmid into RD cells (HA-VR1012 plasmid was used to replenish $2 \mu \mathrm{g} /$ well) for $36 \mathrm{~h}$, cell morphologic analysis with propidium iodide staining by light microscopy (left) or fluorescence microscopy (right). Results are representative of three independent experiments. Bar $=20 \mu \mathrm{m}$. (E) The localization of RIPK3 and HA was analyzed by fluorescence microscopy at $48 \mathrm{~h}$ post-transfection of VR1012-HA and VR1012-3D-HA. Cells were fixed in 4\% paraformaldehyde, stained with RIPK3 and HA antibodies, and then co-stained FITC labeled-secondary antibody (Green, HA) and CoraLite594-conjugated-second antibody (Red, RIPK3). Merged images of HA and RIPK3 are shown. Data are representative of three individual experiments. Scale bar $=10 \mu \mathrm{m}$.

murine cytomegalovirus (Upton et al., 2012), influenza A virus (Thapa et al., 2016), and reovirus (Berger et al., 2017) are among numerous other viruses that have this ability (Upton et al., 2012; Nogusa et al., 2016; Berger et al., 2017; Maelfait, 2017; Schock et al., 2017; Guo et al., 2018; Muraro, 2018; Gaba et al., 2019; Lee et al., 2019). Furthermore, some viruses, such as Epstein-Barr virus (Liu et al., 2018) and human cytomegalovirus (Omoto et al., 2015), can inhibit necroptosis. Therefore, the regulation of necroptosis is a common theme among a subset of viruses, and our results provide a new model to investigate mechanisms associated with necroptosis regulation.

The core of the necroptotic pathway involves the activities of the RIP kinases, RIPK1 and RIPK3, and their ability to phosphorylate and activate the pseudokinase mixed lineage kinase domain-like (MLKL) protein. We demonstrated that
RIPK3 is up-regulated after CA6 infection and that the upregulation of RIPK3 is reversed by the necroptosis inhibitor necrostatin-1, suggesting that RIPK3 may mediate CA6-induced necroptosis. However, the expression of MLKL and p-MLKL was not affected by CA6 infection. Therefore, our results are consistent with the possibility that RIPK3 plays a role in CA6-induced necroptosis that is independent of its ability to phosphorylate MLKL. Future studies to identify downstream effectors of RIPK3 activation in CA6-infected cells may address this possibility.

Necroptosis induced by viral infection has been shown to inhibit viral proliferation (Nogusa et al., 2016; Guo et al., 2018; Lee et al., 2019) or to promote viral magnification (Bozym et al., 2011), depending on the virus and the context. In this study, we demonstrated that necrostatin- 1 inhibits viral production. These results were verified by measurement of VP1 genomic levels and 
protein expression and by assessing the TCID50. In the further study, it was found that necrostatin-1 decreased the extracellular (123-fold), intracellular (2.73-fold), and total (2.54-fold) viral mRNA level, decreased extracellular (229-fold) and total (10fold) virions, which indicated that necrostatin-1 inhibited virus production, especially viral release. Therefore, our results suggest that necroptosis is beneficial to the CA6 virus, especially viral release, although further analysis will be needed to elucidate the exact mechanism.

It has been reported that necroptosis is associated with the generation of ROS (Muraro, 2018). However, in our study, we found that CA6 infection did not increase the ROS level, and scavengers of ROS did not affect the necroptosis induced by CA6 or the production of CA6. As an alternate mechanism, viral $3 \mathrm{D}$ protein was shown to bind RIPK3 protein, but not viral 3C protein. Further study confirmed that $3 \mathrm{D}$ protein up-regulated the expression of RIPK3 and induced necroptosis. Therefore, it is speculated that the virus might directly hijack a factor related to necroptosis to induce necroptosis, which provides a mechanism to explain CA6 induction of necroptosis.

\section{CONCLUSION}

In conclusion, necroptosis is exploited functionally by CA6 to facilitate its production, which suggests a novel therapeutic approach for the treatment and prevention of HFMD.

\section{DATA AVAILABILITY STATEMENT}

All datasets generated for this study are included in the article/Supplementary Material.

\section{REFERENCES}

Abdel-Latif, L., Murray, B. K., Renberg, R. L., O’Neill, K. L., Porter, H., Jensen, J. B., et al. (2006). Cell death in bovine parvovirus-infected embryonic bovine tracheal cells is mediated by necrosis rather than apoptosis. J. Gen. Virol. 87(Pt 9), 2539-2548. doi: 10.1099/vir.0.81915-0

Anh, N. T., Nhu, L. N. T., Van, H. M. T., Hong, N. T. T., Thanh, T. T., Hang, V. T. T., et al. (2018). Emerging coxsackievirus A6 causing hand, foot and mouth disease, vietnam. Emerg. Infect. Dis. 24, 654-662. doi: 10.3201/eid2404. 171298

Baltimore, D. (1964). In Vitro synthesis of viral RNA by the poliovirus RNA polymerase. Proc. Natl. Acad. Sci. U.S.A. 51, 450-456. doi: 10.1073/pnas.51. 3.450

Berger, A. K., Hiller, B. E., Thete, D., Snyder, A. J., Perez, E. Jr., Upton, J. W., et al. (2017). Viral RNA at two stages of reovirus infection is required for the induction of necroptosis. J. Virol. 91:e02404-16. doi: 10.1128/jvi.024 04-16

Bozym, R. A., Patel, K., White, C., Cheung, K. H., Bergelson, J. M., Morosky, S. A., et al. (2011). Calcium signals and calpain-dependent necrosis are essential for release of coxsackievirus B from polarized intestinal epithelial cells. Mol. Biol. Cell 22, 3010-3021. doi: 10.1091/mbc.E11-02-0094

Chan, K. P., Goh, K. T., Chong, C. Y., Teo, E. S., Lau, G., and Ling, A. E. (2003). Epidemic hand, foot and mouth disease caused by human enterovirus 71 , Singapore. Emerg. Infect. Dis. 9, 78-85. doi: 10.3201/eid0901.020112

Chang, S. C., Lin, J. Y., Lo, L. Y., Li, M. L., and Shih, S. R. (2004). Diverse apoptotic pathways in enterovirus 71-infected cells. J. Neurovirol. 10, 338-349. doi: $10.1080 / 13550280490521032$

\section{AUTHOR CONTRIBUTIONS}

JY designed the experiments and wrote the manuscript. JY, SZ, and XY analyzed the results. SZ, XM, WH, YS, JL, YL, and JZ conducted the experiments. JY, SZ, XY, XM, WH, YS, JL, YL, JZ, and SW prepared the viruses, the cell lines, and the reagents, and discussed the data.

\section{FUNDING}

This work was supported by the National Natural Science Foundation of China (81871634 and 81301416) to JY, Postdoctoral Science Foundation of China (2014M561302 and 2015T80299) to JY, Norman Bethune Program of Jilin University (2015202) to JY, the Jilin Provincial Science and Technology Department (20140204004YY, 20160414025GH, and 20190304064 YY) to JY, and the Department of Human Resources and Social Security of Jilin Province (2016014) to JY.

\section{ACKNOWLEDGMENTS}

We would like to thank LetPub (www.letpub.com) for providing linguistic assistance during the preparation of this manuscript.

\section{SUPPLEMENTARY MATERIAL}

The Supplementary Material for this article can be found online at: https://www.frontiersin.org/articles/10.3389/fmicb. 2020.00042/full\#supplementary-material

Cho, Y. S., Challa, S., Moquin, D., Genga, R., Ray, T. D., Guildford, M., et al. (2009). Phosphorylation-driven assembly of the RIP1-RIP3 complex regulates programmed necrosis and virus-induced inflammation. Cell 137, 1112-1123. doi: 10.1016/j.cell.2009.05.037

Du, Z., Zhao, Y., Luo, Y., Du, L., Gan, Q., Zhang, H., et al. (2019). Ongoing change of severe hand, foot, and mouth disease pathogens in Yunnan, China, 2012 to 2016. J. Med. Virol. 91, 881-885. doi: 10.1002/jmv.25393

Gaba, A., Xu, F., Lu, Y., Park, H. S., and Liu, G. (2019). The NS1 protein of influenza a virus participates in necroptosis by interacting with MLKL and increasing its oligomerization and membrane translocation. J. Virol. 93:e001835-18. doi: 10.1128/jvi.01835-18

Gao, F., Mao, Q. Y., Chen, P., Bian, L. L., Yao, X., Li, J. X., et al. (2016). Seroepidemiology of coxsackievirus A6, coxsackievirus A16, and enterovirus 71 infections in infants and children: a prospective cohort study in Jiangsu, China. J. Infect. 73, 509-512. doi: 10.1016/j.jinf.2016.08.008

Guo, H., Gilley, R. P., Fisher, A., Lane, R., Landsteiner, V. J., Ragan, K. B., et al. (2018). Species-independent contribution of ZBP1/DAI/DLM-1-triggered necroptosis in host defense against HSV1. Cell Death Dis. 9:816. doi: 10.1038/ s41419-018-0868-3

He, S., Wang, L., Miao, L., Wang, T., Du, F., Zhao, L., et al. (2009). Receptor interacting protein kinase-3 determines cellular necrotic response to TNFalpha. Cell 137, 1100-1111. doi: 10.1016/j.cell.2009.05.021

Laga, A. C., Shroba, S. M., and Hanna, J. (2016). Atypical hand, foot and mouth disease in adults associated with coxsackievirus A6: a clinico-pathologic study. J. Cutan. Pathol. 43, 940-945. doi: 10.1111/cup.12775

Le Clorennec, C., Youlyouz-Marfak, I., Adriaenssens, E., Coll, J., Bornkamm, G. W., and Feuillard, J. (2006). EBV latency III immortalization program 
sensitizes B cells to induction of CD95-mediated apoptosis via LMP1: role of NF-kappaB, STAT1, and p53. Blood 107, 2070-2078. doi: 10.1182/blood-200505-2053

Lee, A. C. Y., Zhang, A. J. X., Chu, H., Li, C., Zhu, H., Mak, W. W. N., et al. (2019). H7N9 influenza A virus activation of necroptosis in human monocytes links innate and adaptive immune responses. Science 10:442. doi: 10.1038/s41419019-1684-0

Li, J. S., Dong, X. G., Qin, M., Feng, H. R., Yang, J. Y., Li, R. X., et al. (2016). Outbreak of hand, foot, and mouth disease caused by coxsackievirus A6 in a Juku in Fengtai District Beijing, China, 2015. Springerplus 5:1650. doi: 10.1186/ s40064-016-3307-x

Li, W., Gao, H. H., Zhang, Q., Liu, Y. J., Tao, R., Cheng, Y. P., et al. (2016). Large outbreak of herpangina in children caused by enterovirus in summer of 2015 in Hangzhou, China. Sci. Rep. 6:35388. doi: 10.1038/srep35388

Li, Z., Yu, J., Liu, L., Wei, Z., Ehrlich, E. S., Liu, G., et al. (2014). Coxsackievirus A16 infection induces neural cell and non-neural cell apoptosis in vitro. PLoS One 9:e111174. doi: 10.1371/journal.pone.0111174

Liu, X., Li, Y., Peng, S., Yu, X., Li, W., Shi, F., et al. (2018). Epstein-Barr virus encoded latent membrane protein 1 suppresses necroptosis through targeting RIPK1/3 ubiquitination. Cell Death Dis. 9:53. doi: 10.1038/s41419-017-0081-9

Lu, J. R., Lu, W. W., Lai, J. Z., Tsai, F. L., Wu, S. H., Lin, C. W., et al. (2013). Calcium flux and calpain-mediated activation of the apoptosis-inducing factor contribute to enterovirus 71-induced apoptosis. J. Gen. Virol. 94(Pt 7), 14771485. doi: 10.1099/vir.0.047753-0

Maelfait, J. (2017). Sensing of viral and endogenous RNA by ZBP1/DAI induces necroptosis. Cell Death Dis. 36, 2529-2543. doi: 10.15252/embj.201796476

Mirand, A., le Sage, F. V., Pereira, B., Cohen, R., Levy, C., Archimbaud, C., et al. (2016). Ambulatory pediatric surveillance of hand, foot and mouth disease as signal of an outbreak of coxsackievirus A6 infections, France, 2014-2015. Emerg. Infect. Dis. 22, 1884-1893. doi: 10.3201/eid2211.160590

Muraro, S. P. (2018). Respiratory syncytial virus induces the classical ROSDEPENDENT NETosis through PAD-4 and necroptosis pathways activation. Sci. Rep. 8:14166. doi: 10.1038/s41598-018-32576-y

Nogusa, S., Thapa, R. J., Dillon, C. P., Liedmann, S., Oguin, T. H. III, Ingram, J. P., et al. (2016). RIPK3 Activates Parallel Pathways of MLKL-Driven necroptosis and FADD-mediated apoptosis to protect against influenza a virus. Cell Host Microb. 20, 13-24. doi: 10.1016/j.chom.2016.05.011

Omoto, S., Guo, H., Talekar, G. R., Roback, L., Kaiser, W. J., and Mocarski, E. S. (2015). Suppression of RIP3-dependent necroptosis by human cytomegalovirus. J. Biol. Chem. 290, 11635-11648. doi: 10.1074/jbc.M115. 646042

Orzalli, M. H., and Kagan, J. C. (2017). Apoptosis and necroptosis as host defense strategies to prevent viral infection. Trends Cell Biol. 27, 800-809. doi: 10.1016/ j.tcb.2017.05.007

Qi, M., Fan, S., Yao, G., Li, Z., Zhou, H., Tashiro, S., et al. (2013). Pseudolaric acid B-induced autophagy contributes to senescence via enhancement of ROS generation and mitochondrial dysfunction in murine fibrosarcoma L929 cells. J. Pharmacol. Sci. 121, 200-211. doi: 10.1254/jphs.12269fp

Reed, L. J., and Muench, H. (1983). A simple method of estimating fifty percent endpoints. J. Hyg. 27, 493-497. doi: 10.1093/oxfordjournals.aje.a118408

Schenk, B., and Fulda, S. (2015). Reactive oxygen species regulate Smac mimetic/TNFalpha-induced necroptotic signaling and cell death. Sci. Rep. 34, 5796-5806. doi: 10.1038/onc.2015.35

Schock, S. N., Chandra, N. V., Sun, Y., Irie, T., and Kitagawa, Y. (2017). Induction of necroptotic cell death by viral activation of the RIG-I or STING pathway. Cell Death Differ. 24, 615-625. doi: 10.1038/cdd.2016.153

Solomon, T., Lewthwaite, P., Perera, D., Cardosa, M. J., McMinn, P., and Ooi, M. H. (2010). Virology, epidemiology, pathogenesis, and control of enterovirus 71. Lancet Infect. Dis. 10, 778-790. doi: 10.1016/S1473-3099(10)70194-8

Song, F., Yu, X., Zhong, T., Wang, Z., Meng, X., Li, Z., et al. (2018). Caspase-3 inhibition attenuates the cytopathic effects of EV71 infection. Front. Microbiol. 9:817. doi: 10.3389/fmicb.2018.00817

Takemoto, K., Hatano, E., Iwaisako, K., Takeiri, M., Noma, N., Ohmae, S., et al. (2014). Necrostatin-1 protects against reactive oxygen species (ROS)-induced hepatotoxicity in acetaminophen-induced acute liver failure. FEBS Open Bio. 4, 777-787. doi: 10.1016/j.fob.2014.08.007

Teng, X., Keys, H., Jeevanandam, A., Porco, J. A. Jr., Degterev, A., Yuan, J., et al. (2007). Structure-activity relationship study of $[1,2,3]$ thiadiazole necroptosis inhibitors. Bioorg. Med. Chem. Lett. 17, 6836-6840. doi: 10.1016/j.bmcl.2007. 10.024

Thapa, R. J., Ingram, J. P., Ragan, K. B., Nogusa, S., Boyd, D. F., Benitez, A. A., et al. (2016). DAI senses influenza a virus genomic RNA and activates RIPK3dependent cell death. Cell Host Microb. 20, 674-681. doi: 10.1016/j.chom.2016. 09.014

Upton, J. W., Kaiser, W. J., and Mocarski, E. S. (2012). DAI/ZBP1/DLM-1 complexes with RIP3 to mediate virus-induced programmed necrosis that is targeted by murine cytomegalovirus vIRA. Cell Host Microb. 11, 290-297. doi: 10.1016/j.chom.2012.01.016

Wang, S. H., Wang, A., Liu, P. P., Zhang, W. Y., Du, J., Xu, S., et al. (2018). Divergent pathogenic properties of circulating coxsackievirus A6 associated with emerging hand, foot, and mouth disease. J. Virol. 92:e00303-18. doi: 10. 1128/jvi.00303-18

Wang, Z., Wang, Y., Wang, S., Meng, X., Song, F., Huo, W., et al. (2018). Coxsackievirus A6 induces cell cycle arrest in G0/G1 phase for viral production. Front. Cell Infect. Microbiol. 8:279. doi: 10.3389/fcimb.2018.00279

Wang, W., Fang, Y., Sima, N., Li, Y., Li, W., Li, L., et al. (2011). Triggering of death receptor apoptotic signaling by human papillomavirus $16 \mathrm{E} 2$ protein in cervical cancer cell lines is mediated by interaction with c-FLIP. Apoptosis 16, 55-66. doi: 10.1007/s10495-010-0543-3

Wang, X., Zhu, C., Bao, W., Zhao, K., Niu, J., Yu, X. F., et al. (2012). Characterization of full-length enterovirus 71 strains from severe and mild disease patients in northeastern China. PLoS One 7:e32405. doi: 10.1371/ journal.pone.0032405

Wang, Z. Y., Zhong, T., Wang, Y., Song, F. M., Yu, X. F., Xing, L. P., et al. (2017). Human Enterovirus 68 interferes with the host cell cycle to facilitate viral production. Front. Cell Infect. Microbiol. 7:29. doi: 10.3389/fcimb.2017.00029

Westendorp, M. O., Frank, R., Ochsenbauer, C., Stricker, K., Dhein, J., Walczak, H., et al. (1995). Sensitization of T cells to CD95-mediated apoptosis by HIV-1 Tat and gp120. Nature 375, 497-500. doi: 10.1038/375497a0

Yang, M. L., Huang, T. S., Lee, Y., and Lu, F. J. (2002). Free radical scavenging properties of sulfinpyrazone. Free Radic. Res. 36, 685-693. doi: 10.1080/ 1071576029009137

Yu, J. H., Zhang, L. Y., Ren, P. Y., Zhong, T., Li, Z. L., Wang, Z. Y., et al. (2015). Enterovirus 71 mediates cell cycle arrest in $S$ phase through non-structural protein 3D. Cell Cycle 14, 425-436. doi: 10.4161/15384101.2014.980631

Zhang, T., Zhang, Y., Cui, M., Jin, L., Wang, Y., Lv, F., et al. (2016). CaMKII is a RIP3 substrate mediating ischemia- and oxidative stress-induced myocardial necroptosis. Nat. Med. 22, 175-182. doi: 10.1038/nm.4017

Zhong, T., Zhang, L. Y., Wang, Z. Y., Wang, Y., Song, F. M., Zhang, Y. H., et al. (2017). Rheum emodin inhibits enterovirus 71 viral replication and affects the host cell cycle environment. Acta Pharmacol. Sin. 38, 392-401. doi: 10.1038/aps. 2016.110

Zhu, N., Khoshnan, A., Schneider, R., Matsumoto, M., Dennert, G., Ware, C., et al. (1998). Hepatitis C virus core protein binds to the cytoplasmic domain of tumor necrosis factor (TNF) receptor 1 and enhances TNF-induced apoptosis. J. Virol. 72, 3691-3697. doi: 10.1128/jvi.72.5.3691-3697.1998

Conflict of Interest: The authors declare that the research was conducted in the absence of any commercial or financial relationships that could be construed as a potential conflict of interest.

Copyright (c) 2020 Zhang, Yu, Meng, Huo, Su, Liu, Liu, Zhang, Wang and Yu. This is an open-access article distributed under the terms of the Creative Commons Attribution License (CC BY). The use, distribution or reproduction in other forums is permitted, provided the original author(s) and the copyright owner(s) are credited and that the original publication in this journal is cited, in accordance with accepted academic practice. No use, distribution or reproduction is permitted which does not comply with these terms. 